\title{
Thermal effect on larval development of the European stag beetle, Lucanus cervus
}

\author{
Arno Thomaes ${ }^{1, *}$, Paul Hendriks ${ }^{2} \&$ Maria Fremlin $^{3}$ \\ ${ }^{1}$ Research Institute for Nature and Forest (INBO), Havenlaan 88 bus 73, 1000 Brussels, Belgium. \\ ${ }^{2}$ Hoofdstraat 243, 9828 PC Oostwold, The Netherlands. Email: hendriksmast@home.nl \\ ${ }^{3} 25$ Ireton Road, Colchester CO3 3AT, UK. Email: mariafremlin@gmail.com
}

*Corresponding author: Arno.thomaes@inbo.be; tel.: +32 4785621 11; fax number: +32 25250300

\begin{abstract}
Conservation of the threatened and protected European stag beetle (Lucanus cervus) mainly focuses on the availability of dead wood as larval habitat. However, as the larval ecology of this species remains poorly studied, less attention has been given to other habitat requirements such as ambient temperatures for the development of the larvae. To design proper guidelines for the preservation of this iconic species, the growth of stag beetle larvae is compared between outdoor containers under a warm sunny and those in a cold shady treatment. Populations originated from the Veluwe (Netherlands) and Colchester (United Kingdom). The shady microclimate led to lower temperatures, which resulted in higher larval weights before molting and an additional year to complete larval development for a part of the population. However, weights were lower than in the warm microclimate when comparing larvae from the same age. This is explained by the longer development time for the different stages. Finally, we found higher larval weights for larvae originating from the Veluwe (Netherlands) compared with larvae from Colchester (UK). We conclude that larvae of $L$. cervus can cope with shady, colder microclimates. Larval development time in general takes two to three years and depends on temperature. Larvae grow mainly in the warm season while weight remains constant, or even decreases, during the cold season with an approximate threshold between 10 to $15^{\circ} \mathrm{C}$.
\end{abstract}

Keywords. Relative growth rate, larval development time, temperature effect, size variation, artificial breeding.

Thomaes A., Hendriks P. \& Fremlin M. (2022). Thermal effect on larval development of the European stag beetle, Lucanus cervus. Belgian Journal of Zoology 152: 1-12. https://doi.org/10.26496/bjz.2022.95

\section{Introduction}

The European stag beetle (Lucanus cervus Linnaeus, 1758: Arthropoda: Coleoptera) is listed as near threatened on the European red list (NIETO \& ALEXANDER 2010), but considered endangered or even extinct in many countries in the northern part of its range (MÉNDEZ \& THOMAES). Being a large and charismatic species, it is often considered as a flagship species for the conservation of saproxylic arthropods (THOMAES et al. 2008; HARVEY et al. 2011; CAMPANARO et al. 2016). Due to its rarity and importance as flagship species, the species is listed on the annex II of the European Habitat Directive and nationally protected in many countries (e.g., HARVEY et al. 2011). 
The conservation measures taken for the European stag beetle mainly focus on the availability of suitable dead wood as larval habitat. However, the larval ecology of this species remains poorly studied. Consequently, no clear guidelines can be given about where and how conservation measures are best allocated. Furthermore, several distribution models revealed minimal thermal requirements or thermophilic habitat (urban, south slopes) which have been related to the proposed thermophilic characteristics of the larval breeding sites (PERCY et al. 2000; RINK \& SINSCH 2008; THOMAES et al. 2008; Chefaoui et al. 2011; Della Rocca et al. 2017; Katusic et al. 2017; Della Rocca \& MILANESI 2020). Consequently, the requirements for the larval development might likely interfere with its distribution, habitat selection and possibly also the threats and decline the species is suffering.

Most of the current knowledge of its larval biology is based on captive rearing in terraria (RADNAI 1995; RINK \& SINSCH 2008; HENDRIKS \& MÉNDEZ 2018). In this rather artificial setup with constant temperatures, HENDRIKS \& MÉNDEZ (2018) found that the larval weight increased mainly in the first 100 days of the L3 stage and then levelled off reaching a maximal weight, known as a saturating growth. Based on various experiments and field observations, various lengths for the larval development of L. cervus have been reported ranging from two to eight years (KLAUSNITZER 1995; RADNAI 1995; SpreCher-UEbersaX 2001; SMith 2003; RinK \& SinsCh 2008; HARVEY et al. 2011; FremLin 2013; HENDRIKS \& MÉNDEZ 2018). A more precise description of the larval development time is needed to estimate, for example, the response time on conservation actions. The quality of the substrate might influence the development time and final size of L. cervus adults (RINK \& SinSCH 2008; HENDRIKS \& MÉNDEZ 2018). Furthermore, the effect of the temperature and humidity on the duration of larval development time and larval growth rate of $L$. cervus remains largely unknown. Temperature might be important as it has a direct influence on the metabolic rate (a threshold of $13^{\circ} \mathrm{C}$ has been suggested by PAWLOWSKI 1961). In captivity, L. cervus is known not to tolerate temperatures higher than $26^{\circ} \mathrm{C}$ (LAI \& KO 2008). RINK \& SINSCH (2008) observed that they were active during the winter at $4^{\circ} \mathrm{C}$. Based on radio telemetry in Belgium, a preference for open (warm) canopies for egg deposition sites was demonstrated (THOMAES et al. 2018). Further south, egg deposition sites in Italy detected by the same technique were found under closed canopies (TINI et al. 2017). Despite the fact that no sound evidence of a thermal effect on the larval development time or larval growth rate is available in the literature; this assumed thermophilic behaviour is used in conservation guidelines to recommend half open canopies of the breeding sites and prioritising south orientated slopes in its northwestern range (e.g., RINK \& SINSCH 2008; THOMAES et al. 2018).

Finally, the extreme size variation that can be found within stag beetle males of $L$. cervus as well as other Lucanidae has in general been attributed to differences in food quality and temperature (KLAUSNITZER 1995; RINK \& SinSCH 2008; ROMITI et al. 2017; SONGVORAWIT et al. 2018), but the relative importance or interactions between these factors is still poorly understood. SONGVORAWIT et al. (2018) concluded for a tropical Aegus stag beetle that a longer feeding period resulted in larger adults and expected regional differences in feeding period to be related to the length of rainfall season and habitat. HARVEY \& GANGE (2006) found regional variation in size for $L$. cervus which is possibly related to differences in climate and food quality. ROMiтI et al. (2017) described a relation between size and latitudinal cline but a more specific relation with temperature has not been proven for L. cervus, or for other Lucanidae. It has been assumed that a faster development under warm breeding conditions will in general lead to smaller specimens (KlaUSNitZer 1995; SPREChER-UEBERSAX 2001; RinK \& SinSCH 2008).

To assess the thermal effect of an open versus closed canopy on the larval development time and larval growth rate, we set up a rearing experiment with two distinct populations from Western Europe: Veluwe (Netherlands) and Colchester (UK), the former being known to have larger beetles (HARVEY et al. 2011). We hypothesise that larval development will take longer, and larval weight will be higher under the colder shady treatment. 


\section{Material and methods}

\section{Larval origin and experimental setup}

The research was performed in a garden in Oostwold (Netherlands, $53.203^{\circ} \mathrm{N}, 6.440^{\circ} \mathrm{E}$ ) with humus rich sandy soils. Two locations ( $23 \mathrm{~m}$ apart) were selected representing two extreme microhabitats: sunny and shady. The first location was near a sun exposed wall of a house representing an open canopy at a warm microhabitat and the shady location was in the deep shade of a group of trees and shrubs (Betula sp., Fraxinus excelsior Linnaeus, 1753, Prunus laurocerasus Linnaeus, 1753 and Amelanchier lamarckii F.G. Schroed, 1968) representing closed canopy situations resulting in a cold microhabitat. Data loggers (Voltcraft DL-101T, accuracy $0.1^{\circ} \mathrm{C}$ ) registered the temperature every six hours on the warm and cold location in the containers of the larvae, as well as the outdoor air temperature in the shade.

The larvae originated from two populations: the Veluwe (Netherlands) and Colchester (United Kingdom). In 2016, one female was collected at the Veluwe in Hoog Soeren $\left(52.218^{\circ} \mathrm{N}, 5.879^{\circ} \mathrm{E}\right)$ and one in Vierhouten $\left(52.320^{\circ} \mathrm{N}, 5.820^{\circ} \mathrm{E}\right)$ (permit EIS-Nederland FF/75A/2015/034). In Colchester $\left(51.883^{\circ} \mathrm{N}\right.$, $0.884^{\circ} \mathrm{E}$ ), two females were captured and transported to the Netherlands. They were kept in separate terraria to lay eggs and after hatching, the larvae were collected as described in HENDRIKS \& MÉNDEZ (2018).

The outdoor experiment started on the $4^{\text {th }}$ of September 2016 and lasted till the end of 2019. A total of 25 first instar (L1) one week old larvae were placed in four plastic containers, six larvae each, except one that had seven. Each container represents a different combination of source population (Veluwe and Colchester) and temperature treatment (warm and cold). Larvae from different females from the same source population were divided equally across both temperature treatments. Lidded plastic containers $(\mathrm{L} \times \mathrm{W} \times \mathrm{H}: 32 \times 25 \times 18 \mathrm{~cm})$ were filled with blocks and pulverized pieces of beech wood. This wood originated from a forest near Roden, the Netherlands, and was likely colonised by tinder fungus (Fomes fomentarius (Linnaeus) Fries, 1849) (see HENDRIKS \& MÉNDEZ 2018 for more information). Two containers were placed in a $40 \mathrm{~cm}$ deep shaft in the ground at the shady location, this shaft was closed off with a $6 \mathrm{~cm}$ thick insulated plate. The shaft was spaced to just fit in the containers so that the soil temperature could settle inside the containers. On the sunny location, two containers were buried to a depth of $20 \mathrm{~cm}$ such that the larvae experienced warm conditions near the soil surface. To prevent overheating by direct sunlight, $3 \mathrm{~cm}$ thick concrete tiles were placed on top of the lid.

The larvae were checked regularly and from day 57 onwards, they were weighed about monthly $(0.001 \mathrm{gr}$ accuracy) and their head capsule width (HCW) was measured with callipers ( $0.1 \mathrm{~mm}$ accuracy) to determine the larval stage. Furthermore, the combination of HCW and weight allowed to follow the larvae individually in each container (cfr. FREMLIN \& HENDRIKS 2014; HENDRIKS \& MÉNDEZ 2018). New dead wood was supplied monthly when needed.

When larvae were fully grown, started to get yellow and were nearing the pre-pupation stage, a part of the container was filled with soil. Thereafter, the substrate area was still checked until all larvae left for the soil area which was only examined with care in order to not disturb the pupal chambers.

\section{Data analysis}

The analyses were based on the monthly measurements resulting in 300 observations from the 25 initial larvae (study objects).

We analysed the effect of temperature treatment (cold/warm), population origin (Colchester/Veluwe), age and larval stage (L1, L2 and L3) on larval weight by means of a generalized additive mixed model 
(GAMM). The identity of the individual larvae was used as random effect. Age was expressed as the number of days since the start of the experiment divided by 30 which approximates months. This was done to avoid large numbers in the model. A smoother was used on age and combined with larval stage, treatment and population. All interactions were included in a full model on which stepwise backwards selection was applied based on the $\mathrm{p}$-value of the variables.

$$
\text { Weight } \sim \text { s(Age, by }=\text { Stage: Treatment: Population), random effect }=\text { Individual }
$$

In a second model, we tested the effect of growing degree days (GDD) on relative growth rate (RGR) expressing the weight increase as percentage.

$$
\mathrm{RGR}_{\text {age: }}=\left(\text { Weight } t_{\text {age:i }}-\text { Weight }_{\text {age:i-1 }}\right) / \text { Weight }_{\text {age: }-1} * 100 \%
$$

GDD were calculated as the time with temperature above $13^{\circ} \mathrm{C}$, cf. a possible physiological threshold for positive metabolic activity (PAWLOWSKI 1961), between each two successive measurements $\left(\mathrm{GDD}_{13^{\circ} \mathrm{C}}\right.$ ). This value was either low ( $<3$ days) during the winter and spring (mainly December to April) or high (21-37 days) during the summer and autumn (mainly June to November), with only two intermediate values (supporting information Fig. S1). Consequently, we modelled the RGR with a linear mixed model (LMM) explained by low and high GDD $\left(\mathrm{GDD}_{13^{\circ} \mathrm{C}}<3\right.$ and $\left.\mathrm{GDD}_{13^{\circ} \mathrm{C}}>20\right)$, treatment (cold/warm), stage (L2/L3) and population (Colchester/Veluwe) as explaining variables and individual larvae as random effect. All interactions were included in a full model on which stepwise backwards selection was applied based on the p-value of the variables.

$$
\text { RGR } \sim \text { GDD * Treatment * Stage * Population, random effect }=\text { Individual }
$$

All statistics were performed using R3.6.1 with packages mgev and nlme (WOOD 2017; R CORE TEAM 2019; PINHEIRO et al. 2021).

\section{Results}

The two temperature treatments significantly (t-paired: -31.304 , df: $2699, \mathrm{p}<0.001$ ) differed about $1{ }^{\circ} \mathrm{C}$ with mean temperatures of $12.7^{\circ} \mathrm{C}$ (s.d.: $5.2^{\circ} \mathrm{C}$ ) and $11.7^{\circ} \mathrm{C}$ (s.d.: $4.9^{\circ} \mathrm{C}$ ) for the warm and cold treatment, respectively. The mean air temperature during the experiment was $10.7^{\circ} \mathrm{C}$ (s.d.: $\left.6.8^{\circ} \mathrm{C}\right)$.

The larvae took either two or three years to reach the pre-pupal stage. Seven larvae died in each of the two treatments (see supporting information Fig. S2). In the warm treatment, all five remaining larvae took two years to reach the pre-pupal stage, whereas in the cold treatment three out of six took three years to reach that stage. In the warm treatment, all reached the L3 stage by July 2017. Larvae of the cold treatment that reached the L3 stage by July 2017 pupated to adults in the summer of 2018. Those that became L3 by September 2017, pupated in the summer of 2019. Furthermore, the larvae that moulted in 2018 were all heavier on 29 October 2017 compared to those that moulted in 2019. Also, the moult to L2 stage differed. Before the first assessment (day 42 of the experiment), all larvae in the warm treatment had already turned into the L2 stage. In the cold treatment, moulting to the L2 stage mainly happened in the same period but in three occasions lasted longer (between 30 October 2016 and 1 July 2017). Furthermore, one larva died in L1 stage between 1 July 2017 and 30 July 2017.

Larval weights for L1 ranged between $0.18-0.40 \mathrm{~g}$, L2 $0.21-2.61 \mathrm{~g}$ and L3 1.88-17.34 $\mathrm{g}$, while head capsule widths ranged between 2.7 to $3.0 \mathrm{~mm}$ for L1, 4.5-6.1 mm for L2 and 8.6-11.1 mm for L3. Final weight before moulting to a next stage for each larva in each larval stage was significantly higher in the cold treatment for L2 and not significantly higher for the L3 stage (Table 1; supporting information Fig. S3). 


\section{TABLE 1}

Mean final weights for warm and cold treatment for each larval stage and statistics of t-test. Abbreviations: $\mathrm{df}=$ degrees of freedom; $*=\mathrm{p}<0.05 ; \mathrm{NS}=$ not significant.

\begin{tabular}{ccccccc}
\hline \multirow{2}{*}{ Stage } & \multicolumn{2}{c}{ Mean final weight (g) } & & t & df & p \\
\cline { 2 - 3 } & Warm & Cold & & & - & - \\
\hline L1 & - & 0.34 & & - & - & $0.04^{*}$ \\
L2 & 1.25 & 2.05 & & 2.347 & 11.001 & $0.23 \mathrm{NS}$ \\
L3 & 9.32 & 11.53 & & 1.287 & 8.970 & \\
\hline
\end{tabular}

The model statistics of the GAMM model explaining the weight are presented in Table 2 and predictions are given in Figure 1. Interactions with population were not significant and consequently removed from the model. Weights from warm treatment were higher for L2 as well as the L3 stage but as 95\% confidence interval overlap, differences were not significant. For the L3 stage, we noticed a strong weight increase in the summer of 2017 till early September. The weight then levelled off during winter to increase again the following spring. In the L1 and L2 stages, no seasonal effects were visible. The larval weights from the Veluwe population were significantly higher than those from Colchester.

The relative growth rate (RGR) varied from -35 to $195 \%$ (mean \pm s.e.: $36 \pm 47 \%$ ). The model selection removed all interaction terms except between stage (L2/L3) and origin (Colchester/Veluwe). From the main terms, treatment was excluded as being not significant (Table 3). The RGR was strongly influenced by the high or low growing degree days (GDD), being close to zero or even negative during the cold season with low GDD. The model also estimated a slightly higher growth rate for L3 compared to L2 but this difference was not significant. The RGR of individuals from the Colchester population in L2 stage was significantly higher than for the L2 stage from the Veluwe population (Fig. 2).

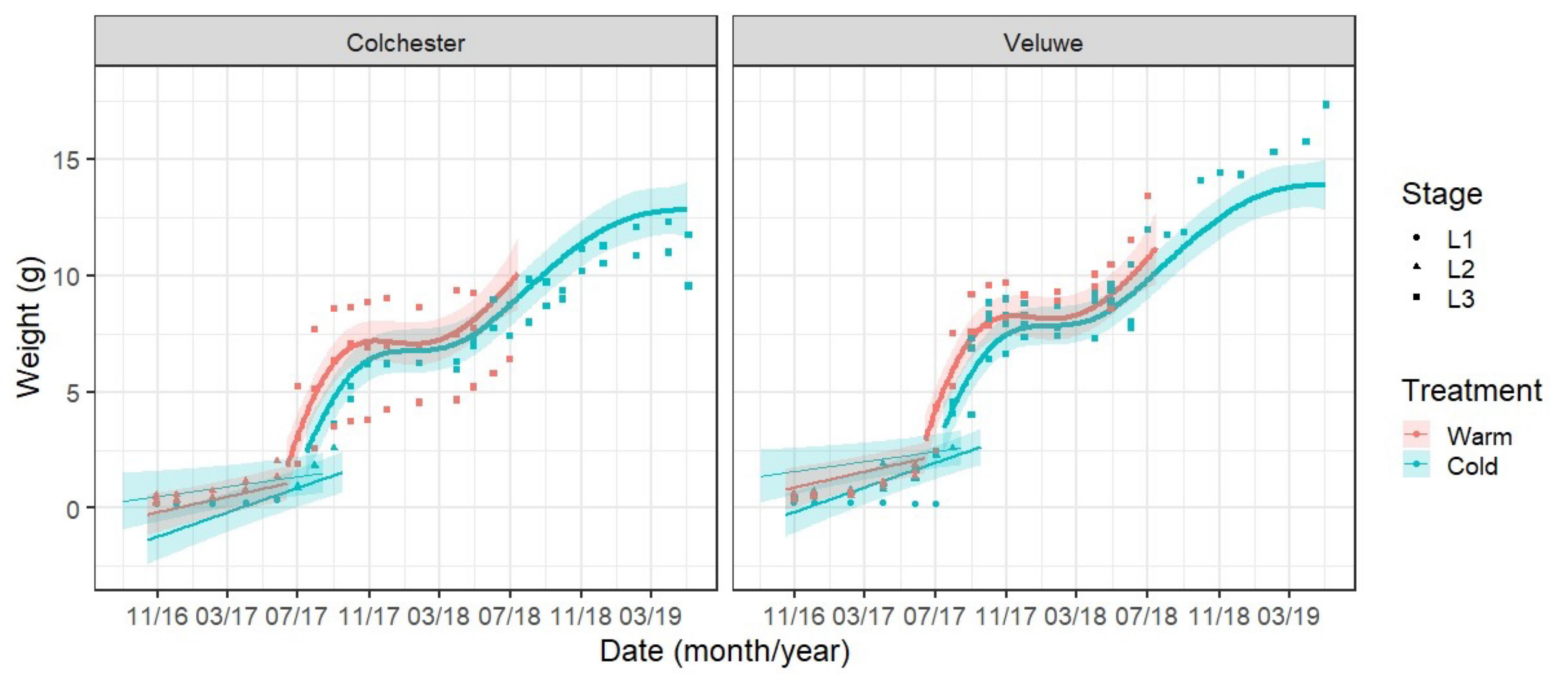

Figure 1 - Weight development of the larvae during the experiment (dots) separated for population origin, stage and treatment and model prediction (line, line tickness represents different larval stages) and $95 \%$ confidence interval as shade. 


\section{TABLE 2}

Model statistics of GAMM model explaining the larval weight. The intercept is set for the Veluwe population. P values for S(Age) effects are based on a comparison between a model with intercept and origin and a model with intercept, origin and age for the given larval stage and treatment. Abbreviation: edf $=$ estimated degrees of freedom.

\begin{tabular}{lccccc}
\hline & Estimate & s.e. & edf & t & p \\
\hline Intercept & 2.77 & 0.41 & 1 & 6.72 & $<0.001$ \\
Origin: Colchester & -1.08 & 0.47 & 1 & -2.33 & 0.034 \\
S(Age): L1.Cold & 0.83 & 0.37 & 1 & 2.25 & 0.025 \\
S(Age): L2.Cold & 2.04 & 0.35 & 1 & 5.78 & $<0.001$ \\
S(Age): L3.Cold & 8.17 & 2.70 & 6.15 & 3.02 & 0.003 \\
S(Age): L2.Warm & 1.31 & 0.36 & 1 & 3.66 & $<0.001$ \\
S(Age): L3.Warm & 14.15 & 8.91 & 4.54 & 1.59 & 0.114 \\
\hline
\end{tabular}

TABLE 3

Model statistics of LMM model explaining the larval growth rate. The intercept was set for the L2 stage, low GDD and Veluwe population.

\begin{tabular}{lcccc}
\hline & Estimate & s.e. & t & P \\
\hline Intercept & -18.48 & 8.59 & -2.15 & 0.034 \\
Stage:L3 & 15.15 & 8.32 & 1.82 & 0.071 \\
GDD:High & 68.67 & 6.55 & 10.48 & $<0.001$ \\
Origin:Colchester & 35.75 & 10.01 & 3.57 & 0.004 \\
Stage:L3 Origin:Colchester & -35.84 & 11.84 & -3.03 & 0.003 \\
\hline
\end{tabular}

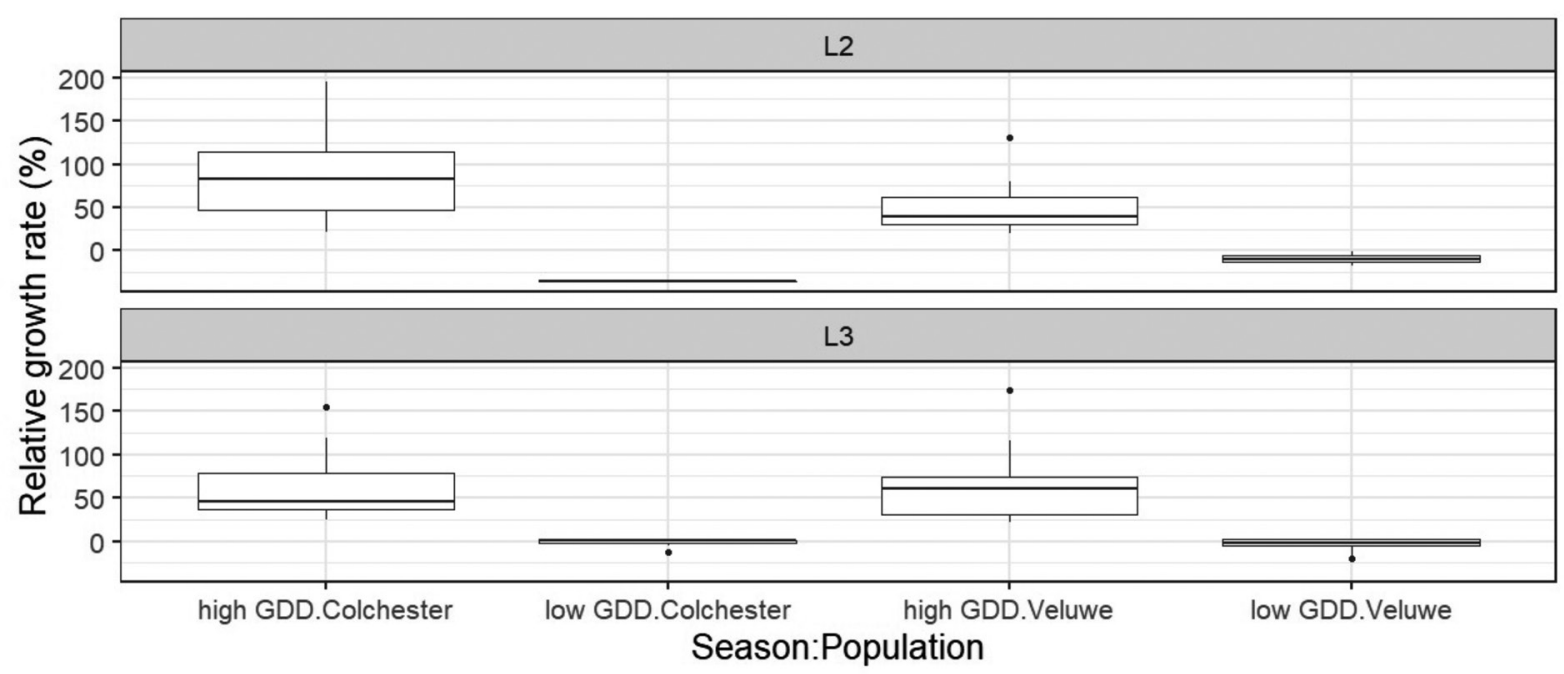

Figure 2 - Boxplots of the relative growth rate separated for larval stage (L2/L3), low and high growing degree days (GDD) and Veluwe and Colchester population. 


\section{Discussion}

Our experiment gives first insight in the thermal effect on the larval ecology of the European stag beetle. It shows that higher final weights are reached before moulting to a next stage in a shady, colder microclimate (significant for L2, higher but not significant for L3). Further, the weight model predicts lower weights in cold microclimate when comparing larvae from the same age. This is explained by the longer development time for the different stages in cold microclimate. This likely results in a longer larval development time under colder conditions. Especially, as the pre-pupation stage always starts at the end of the spring (HARVEY et al. 2011; FREMLIN 2013), a slight delay in development can quickly lead to a one year difference in the complete life cycle. In our study all larvae (five) in the warm treatment developed in two years time while half of the cold treatment larvae took three years to develop (three out of six) but there are not enough data for sound statistics on the overall development time. This longer develoment time seems both related to their weight before the previous winter and feeding period as L3 larvae. Finally, we found no significant difference in relative growth rate between warm and cold treatments, but instead relative growth rate depended on the number of growing degree days (GDD).

We can conclude from our experiment that larval development takes two to three years leading to a life cycle of three to four years. This conclusion is in line with other studies on the larval development in the Northwestern distribution range of the species (RINK \& SINSCH 2008; FREMLIN 2012, 2013; HENDRIKS \& MÉNDEZ 2018).

Larval growth predominantly happens during a warm period whereas their weight remains the same or even decreases in the winter (cfr. RINK \& SINSCH 2008). In our study, the warm period included mainly summer and autumn, while RINK \& SINSCH (2008) found the main growth period to be spring and summer for a more continental climate. HENDRIKS \& MÉNDEZ (2018) found a saturating growth rate for indoor rearing, which was not confirmed in our outdoor experiment as the relative growth rate only levelled off during winter. However, as the larvae in this experiment pupated in different years, the mean relative growth rate over the different larvae was less indicative for the saturated growth rate of an individual larva. Based on this seasonal behaviour, we conclude that summer soil temperature might be more important than winter soil temperature for the development time of the larvae. Furthermore, larvae might optimise their depth differently during winter and summer periods.

Larval depth ranges mainly between soil surface and $20 \mathrm{~cm}$ depth and rarely down to $40 \mathrm{~cm}$ (RINK \& SinsCH 2008; HAWES 2009; FREMLin 2013). Also Tini et al. (2017) reported that half of the egg deposition sites referred to lying trees indicating a shallow habitat. As the summer temperature decreases with soil depth, longer development time might be expected with increasing depth. On the other hand, a shallow soil depth might be less optimal as it has higher fluctuating temperatures and moisture content and is also more prone to predation. In winter, the optimal depth might be mainly explained as avoiding frost (RINK \& SINSCH 2008) and drowning, depending on the local winter water table. Due to different requirements in winter and summer, optimal depth will likely depend on the season causing larvae to migrate to optimise these factors accordingly.

To model the relative growth rate, we used a threshold of $13^{\circ} \mathrm{C}$ to split the months into high and low GDD representing a warm and cold season. The fact that these periods showed significant differences in relative growth rate does not necessarily confirm $13^{\circ} \mathrm{C}$ to be a true threshold for this species. Any temperature threshold between about 10 and $15^{\circ} \mathrm{C}$ would have lead to a very similar split in warm and cold season and would also fit the high growth in summer and low to negative growth rate in winter. Therefore, to asses the exact threshold defining the growing degree days, a more experimental set up should be used. Larvae of the European stag beetle remain active in the winter, even at $4^{\circ} \mathrm{C}$ they move around (RINK \& SINSCH 2008). Furthermore, HENDRIKS (unpublished) performed a small assimilation experiment which confirmed larval growth for temperatures above $16^{\circ} \mathrm{C}$ and negative or close to zero 
growth rate below $11^{\circ} \mathrm{C}$ but production of frass (faecal pellets) continued even at $6^{\circ} \mathrm{C}$. This contrasts with the findings for Dorcus parallelipipedus Linaeus, 1758 , which has a winter diapause (by emptying its gut and becoming immobile) at temperatures below $6^{\circ} \mathrm{C}$ (HENDRIKS 2019). This difference could be linked to the fact that larvae of $D$. parallelipipedus as well as some other lucanids with a diapause live above ground (NEVEN et al. 1986; HENDRIKS 2019) in contrast to larvae of L. cervus which live underground, where temperatures are much more buffered. Furthermore, larvae of $L$. cervus are capabale to move up and down to find more optimal temperatures. Consequently, it might be possible that growth of $L$. cervus is not suddenly limited by a certain temperature threshold but that growth decreases more gradualy with decreasing temperatures within a certain range. RINK \& SINSCH (2008) concluded that the suitable breeding habitat in thermally unfavorable areas (closed forests) is apparently not populated as long as warmer, sunny breeding sites (urban sites) are available. This conclusion was confirmed by different distribution models with a preference for thermophile and urban sites (THOMAES et al. 2008; Chefaoui et al. 2011; Della Rocca et al. 2017; Katusic et al. 2017; Della RocCA \& Milanesi 2020). However, we hypothesize that shorther life cycles at these warmer sites might compensate local threats (e.g., limited dead wood continuity) resulting in higher population survival while in shaded forest conditions, the habitat requirements to ensure the longer life cycle might be no longer met.

Finally, a population effect was found in the weight model indicating higher weights for the population of the Veluwe. A similar result was reported for wild larvae with head capsule width and maximum weights of L3 stage larvae being higher for the population of the Veluwe than Colchester (FREMLIN \& HENDRIKS 2014). HARVEY et al. (2011) also found a difference in male adult size between UK and mainland Europe populations and related this to an urban versus a forest habitat of these populations. Also SONGVORAWIT et al. (2018) discovered an urbanisation effect for an Aegus stag beetle species for which males collected from natural populations as well as bred offspring were bigger in forest habitat as compared to urban habitat. This urbanisation effect has also been described for other beetle species (AlARUiKKa et al. 2002; MAGURA et al. 2006; UlRICH et al. 2008; Foster et al. 2020).

Previous studies already highligted the importance of food quality for the size of adult stag beetles (HENDRIKS \& MÉNDEZ 2018). The relative importance of temperature and food quality or potentential interactions between them should be addressed in future studies. But we hypothesize that the food quality will be of main importance for the larval weight while temperature will have the strongest effect on development time.

Due to the limited number of larvae used in this experiment, conclusions must be drawn carefully. A study with a larger number of larvae would be needed in order to confirm or disprove the findings of the current paper.

We can conclude that larvae of $L$. cervus can cope with shady, colder microclimates but that it may lead to longer development time and finally result in an additional year of development for part of the population, likely resulting in higher final weights and larger adults. In the Northwestern distribution range, larval development takes two to three years in general, leading to a life cycle of three to four years. In addition, we show that growth happened mainly in the summer half of the year while growth rate was close to zero in the winter half. We observed an approximate temperature threshold for larval growth between 10 and $15^{\circ} \mathrm{C}$.

\section{Acknowledgments}

We would like to acknowledge R.M.J.C. Kleukers, J.T. Smit and EIS-Nederland for granting the permit FF/75A/2015/034 and its follow up. Thanks to A. Mirzaie, who performed an internship at the first authors institute and worked on a data exploration on a preliminary data set of this experiment. 
THOMAES A. et al., Thermal effect on European stag beetle larvae

\section{References}

AlaruikKa D., KotZe D.J., MatVeinen K. \& Niemela J. (2002). Carabid beetle and spider assemblages along a forested urban-rural gradient in southern Finland. Journal of Insect Conservation 6: 195-206. https://doi.org/10.1023/A:1024432830064

Campanaro A., Zapponi L., Hardersen S., Méndez M., Al Fulaij N., Audisio P., Bardiani M., Carpaneto G. M., Corezzola S., Della Rocca F., Harvey D., Hawes C., Kadej M., Karg J., Rink M., Smolis A., Sprecher E., Thomaes A., Toni I., Vrezec A. L., Zauli A., Zilioli M. \& CHIARI S. (2016). A European monitoring protocol for the stag beetle, a saproxylic flagship species. Insect Conservation and Diversity 9: 574-584. https://doi.org/10.1111/icad.12194

Chefaoui R.M., Lobo J.M. \& Hortal J. (2011). Effects of species traits and data characteristics on distribution models of threatened invertebrates. Animal Biodiversity and Conservation 34: 229-247.

Della Rocca F. \& Milanesi P. (2020). Combining climate, land use change and dispersal to predict the distribution of endangered species with limited vagility. Journal of Biogeography 45: 1427-1438. https://doi.org/10.1111/jbi.13804

Della Rocca F., Bogliani G., \& Milanesi P. (2017). Patterns of distribution and landscape connectivity of the stag beetle in a human-dominated landscape. Nature Conservation, Bulgaria 19: 19-37. https://doi.org/10.3897/natureconservation.19.12457

Foster C.W., Kelly C., Rainey J.J. \& Holloway G.J. (2020). Effects of urbanisation and landscape heterogeneity mediated by feeding guild and body size in a community of coprophilous beetles. Urban Ecosystems 23: 1063-1077.

FREMLIN M. (2012). Stag beetle sightings on false-acacia stumps. Nature in North-East Essex 2012: $76-80$.

FREMLIN M. (2013). Results of the "Stag beetle larval incidents in private gardens" survey. Essex Naturalist (New Series) 30: 94-106.

FREMLIN M. \& HENDRIKS P. (2014). Number of instars of Lucanus cervus (Coleoptera: Lucanidae) larvae. Entomologische Berichten 70: 115-120.

HARVEY D. \& GANGE A.C. (2006). Size variation and mating success in the stag beetle, Lucanus cervus. Physiological Entomology 31: 218-226. https://doi.org/10.1111/j.1365-3032.2006.00509.x

Harvey D., Gange A., Hawes C., RinK M., Abdehalden M., Al Fulaij N., Asp T., Ballerio A., Bartolozzi L., Brustel H., Cammaerts R., Carpaneto G.M., Cederberg B., Chobot K., Cianferoni F., Drumont A., Ellwanger G., Ferreira S., Grosso-Silva J.M., Gueorguiev B., Harvey W., Hendriks P., Istrate P., JansSon N., Jelaska L.S., JendeK E., Jović M., KerVyn T., Krenn H.W., Kretschmer K., Legakis A., Lelo S., Moretti M., Merkl O., Palma R.M., Neculiseanu Z., Rabitsch W., Rodríguez S.M., Smit J.T., Smith M., Sprecher-Uebersax E., Telnov D., Thomaes A., Thomsen P.F., Tykarski P., Vrezec A., Werner S. \& Zach P. (2011). Bionomics and distribution of the stag beetle, Lucanus cervus (L.) across Europe. Insect Conservation and Diversity 4: 23-38. https://doi.org/10.1111/j.1752-4598.2010.00107.x

HAWES C. (2009). The stag beetle: Some aspects of larval ecology. White Admiral 73: 20-23.

HENDRIKS P. (2019). Life cycle length of the lesser stag beetle (Coleoptera: Lucanidae: Dorcus parallelipipedus). Entomologische Berichten 79: 208-216.

HENDRIKS P. \& MÉNDEZ M. (2018). Larval feeding ecology of the stag beetle Lucanus cervus (Coleoptera: Lucanidae). Entomologische Berichten 78: 205-217. 
KATUŠIĆ L., JELASKA S.D. \& JELASKA L.Š. (2017). Monitoring of saproxylic beetles in Croatia: following the path of the stag beetle. Nature Conservation, Bulgaria 19: 39-56. https://doi.org/10.3897/natureconservation.19.12683

KlausnitZer B. (1995). Die Hirschkäfer: Lucanidae. Spektrum Akademischer Verlag, Heidelberg.

LAI J. \& Ko H.P. (2008). For the Love of Rhinoceros and Stag Beetles: Second edition. PSK, Taiwan.

Magura T., Tothmeresz B. \& Lovei G.L. (2006). Body size inequality of carabids along an urbanisation gradient. Basic and Applied Ecology 7: 472-82. https://doi.org/10.1016/j.baae.2005.08.005

MÉNDEZ M. \& THOMAES A. (2020). Biology and conservation of the European stag beetle: recent advances and lessons learned. Insect Conservation and Diversity 14: 271-284.

https://doi.org/10.1111/icad.12465

Neven L.G., Duman J.G., Beals J.M. \& Castellino F.J. (1986). Overwintering adaptations of the stag beetle, Ceruchus piceus: removal of ice nucleators in the winter to promote supercooling. Journal of Comparative Physiology 156: 707-716. https://doi.org/10.1007/BF00692749

Nieto A. \& AleXAnder K.N.A. (2010). European Red List of Saproxylic Beetles. Publications Office of the European Union, Luxembourg.

PAWLOWSKI J. (1961). Próchnojady blazkorozne w biocenozie leśnej Polski - Lamellicornes cariophages in forest biocenosis of Poland. Ekologia Polska Seria A 9: 355-437.

Percy C., Bassford G. \& Keeble V. (2000). Findings of the 1998 National Stag Beetle Survey. People's Trust for Endangered Species, London.

Pinheiro J., Bates D., Debroy S., SARKar D. \& R Core TeAm (2021). nlme: Linear and Nonlinear Mixed Effects Models. R package version 3.1-152.

Available from https://CRAN.R-project.org/package=nlme [accessed 20 January 2022].

R CORE TEAm (2019). R: A Language and Environment for Statistical Computing. R Foundation for Statistical Computing: Vienna.

RADNAI F. (1995). Un élevage de "cerf-volant” Lucanus cervus Linné, 1758 (Coleoptera, Lucanidae). Insectes 98: 9-12.

RINK M. \& SINSCH U. (2008). Bruthabitat und larvalentwicklung des Hirschkäfers Lucanus cervus (Linnaeus, 1758) (Coleoptera: Lucanidae). Entomologische Zeitschrift 118: 229-236.

Romiti F., De Zan L.R., De Gasperis S.R., Tini M., Scaccini D., Anaclerio M. \& CARPaneto G.M. (2017). Latitudinal cline in weapon allometry and phenology of the European stag beetle. Nature Conservation, Bulgaria 19: 57-80. https://doi.org/10.3897/natureconservation.19.12681

Smith M. (2003). National Stag Beetle Survey 2002. People's Trust for Endangered Species, London.

Songvorawit N., Butcher B.A. \& Chaisuekul C. (2018). Captive breeding reveals larval performance and adult body size differences between two geographical populations of the stag beetle Aegus chelifer chelifer (Coleoptera: Lucanidae). Journal of Asia-Pacific Entomology 21: 708-715. https://doi.org/10.1016/j.aspen.2018.04.001

SPRECHER-UEBersax E. (2001). Studien zur Biologie und Phänologie des Hirschkäfers im Raum Basel, mit Empfehlungen von Schutzmassnahmen zur Erhaltung und Förderung des Bestandes in der Region (Coleoptera: Lucanidae, Lucanus cervus L.). Universität Basel, Basel.

THOMAes A., KeRVYN T. \& MAES D. (2008). Applying species distribution modelling for the conservation of the threatened saproxylic Stag Beetle (Lucanus cervus). Biological Conservation 141: 1400-1410. https://doi.org/10.1016/j.biocon.2008.03.018 
Thomaes A., Dhont P., Dekeukeleire D. \& Vandekerkhove K. (2018). Dispersal behaviour of female stag beetles (Lucanus cervus) in a mosaic landscape: when should I stay and where should I go. Insect Conservation and Diversity 11: 523-533. https://doi.org/10.1111/icad.12325

Tini M., Bardiani M., Campanaro A., Mason F., Audisio P. \& CARPaneto G.M. (2017). Detection of stag beetle oviposition sites by combining telemetry and emergence traps. Nature Conservation, Bulgaria 19: 81-96. https://doi.org/10.3897/natureconservation.19.12678

UlRICH W., KOMOSINSKI K. \& ZALEWSKI M. (2008). Body size and biomass distributions of carrion visiting beetles: do cities host smaller species? Ecological Research 23: 241-248.

https://doi.org/10.1007/s11284-007-0369-9

Wood S.N. (2017). Generalized Additive Models: An Introduction with $R$ ( $2^{\text {nd }}$ edition). Chapman and Hall/CRC, Boca Raton. https://doi.org/10.1201/9781315370279

Manuscript received: 10 June 2021

Manuscript accepted: 13 January 2022

Published on: 3 February 2022

Branch editor: Frederik Hendrickx

\section{Supporting Information}

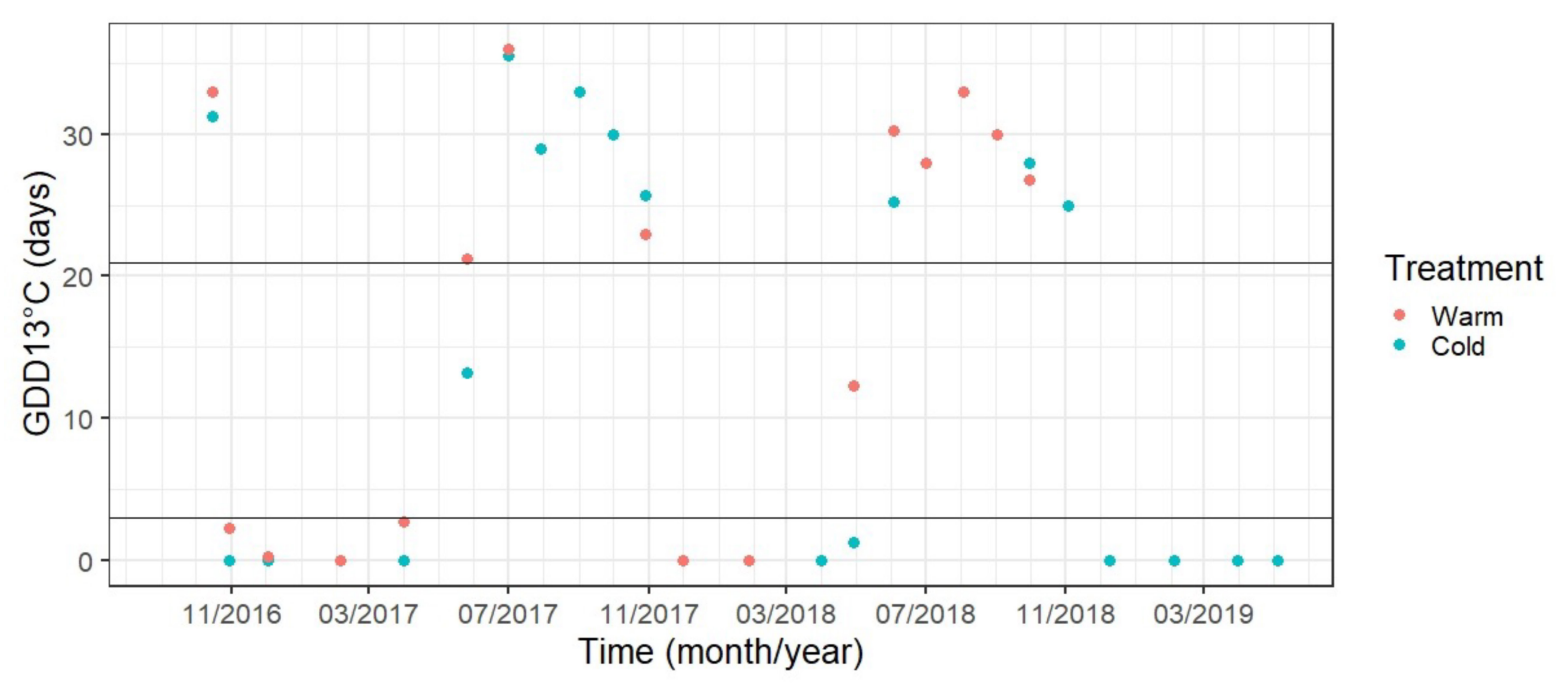

Figure $\mathrm{S} 1$ - Growing degree days $\left(\mathrm{GDD}_{13^{\circ} \mathrm{C}}\right)$ during the experiment for the warm and cold treatment with thresholds for low and high GDD set as lines. 


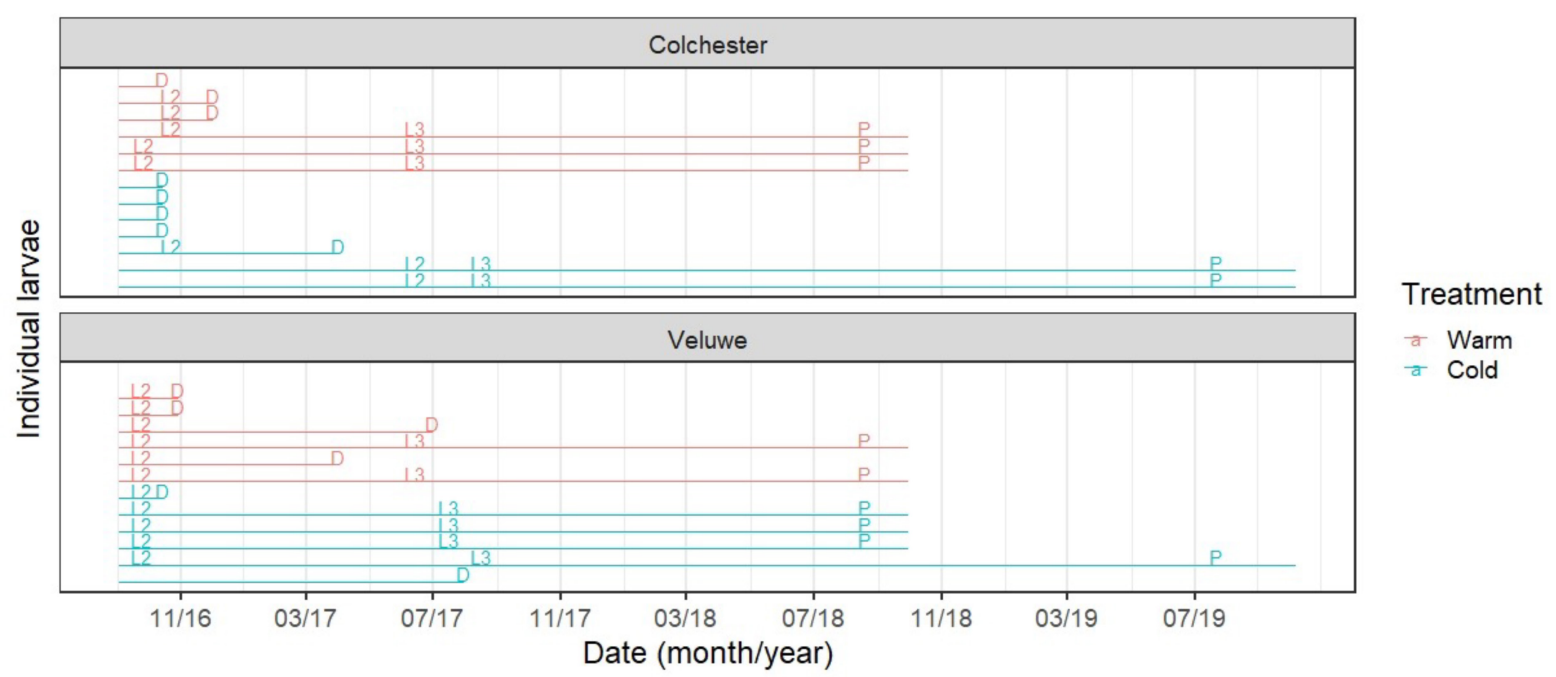

Figure S2 - Life of the different larvae represented by lines separated for population origin and treatment. Abbreviations: $\mathrm{D}=$ dead; $\mathrm{L} 2=$ moulting from $\mathrm{L} 1$ to $\mathrm{L} 2 ; \mathrm{L} 3=$ moulting from $\mathrm{L} 2$ to $\mathrm{L} 3 ; \mathrm{P}=$ moulting from L3 to pupa.

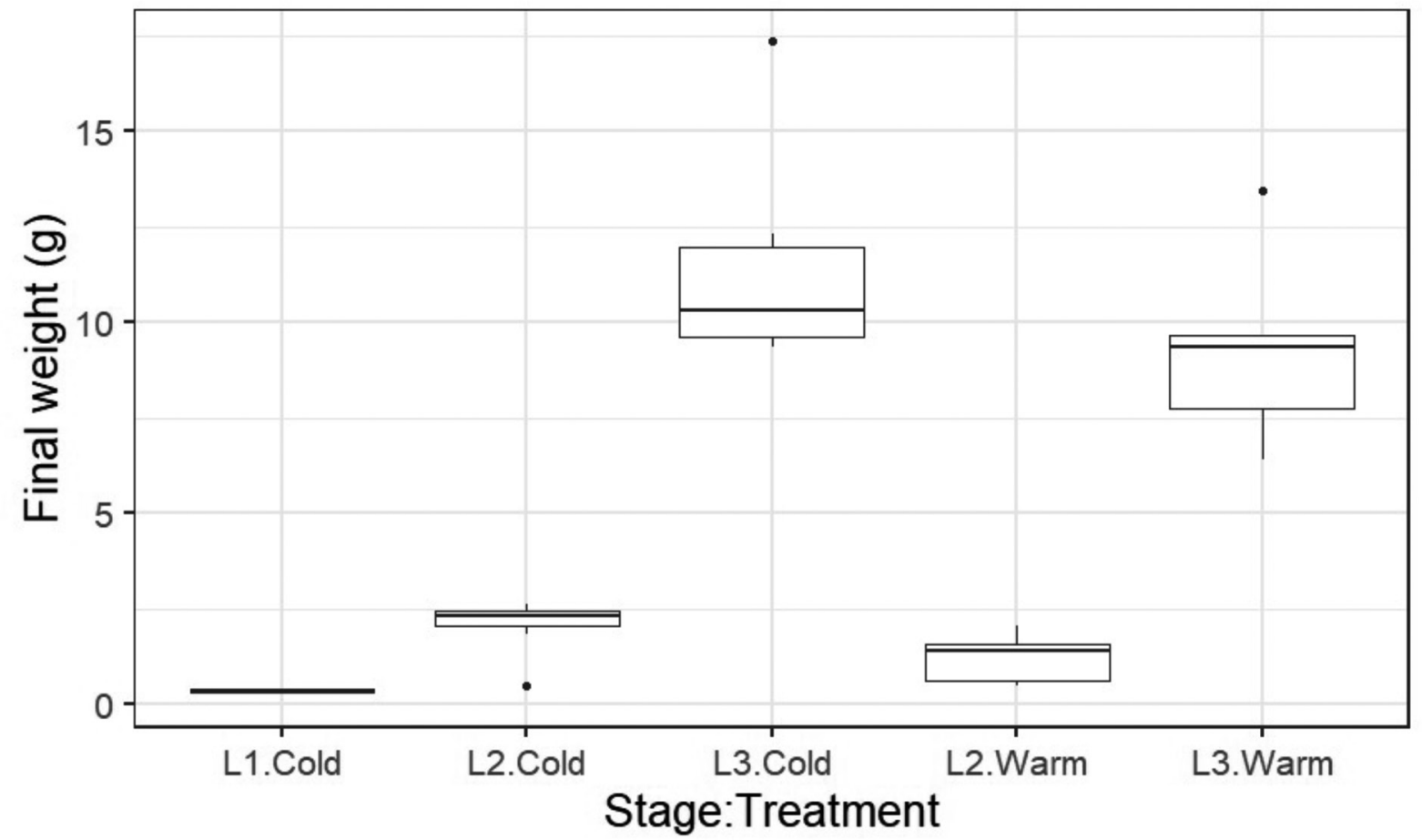

Figure S3 - Boxplots of the final weight separated for larval stage (L1/L2/L3) and warm and cold treatment. 